\title{
Internal carotid artery occlusion in a young female with mitral valve prolapse.
}

\author{
M.A. Saadah ${ }^{1}$, R.A. Shakir ${ }^{1}$, M.A. Rudwan ${ }^{1}$ and N. Khan ${ }^{3}$ \\ Departments of ${ }^{l}$ Neurology and ${ }^{2}$ Radiology, Ibn Sina Hospital, Kuwait and ${ }^{3}$ Department of Cardiology, Chest \\ Hospital, Kuwait.
}

\begin{abstract}
Summary: A healthy 28 year old housewife presented with sudden right hemiplegia and aphasia. No predisposing factors could be ascertained apart from posterior cusp mitral valve prolapse on two dimensional echocardiography. Extensive investigations confirmed the presence of cerebral infarction and persistent occlusion of the left internal carotid artery near its origin.
\end{abstract}

\section{Introduction}

Mitral valve prolapse (MVP) is commonly noted in asymptomatic subjects, where it may be seen in $6 \%$ of females and a lesser percentage of males (Procacci $e t$ al., 1976; Markiewicz et al., 1976). It is also generally regarded as a benign condition, although several major complications are recognized. These include transient cerebral ischaemic episodes, strokes and visual disturbances in addition to various cardiac complications (Barnett et al., 1976; Barnett, 1982; Sandok \& Giuliani, 1982; Beton et al., 1983; Kouvaras \& Bacoulas, 1984). The association with embolic cerebrovascular disease was first reported by Barnett et al. (1976). In a further report the association was confirmed and it was suggested that this was more true in the younger patient with a stroke, where MVP was noted in $40 \%$ of a population of patients with stroke compared to $6.8 \%$ of an age-matched control group (Barnett et al., 1980).

Occlusion of the internal carotid artery in a patient with MVP and a stroke has been reported previously in two patients. The first was in a 21 year old female, where the occlusion was at the origin of the vessel in the neck (Barnett et al., 1980). The second was in a 55 year old man in whom the occlusion was at the siphon (Watson, 1979).

We report a case where the occlusion was near the origin of the internal carotid artery in a 28 year old female with MVP.

Correspondence: M.A. Saadah, M.R.C.P., P.O. Box 18069, Farwaniya, Kuwait, Arabian Gulf.

Accepted: 21 July 1986

\section{Case report}

A 28 year old housewife suddenly fell to the ground with right-sided hemiplegia and aphasia. She had

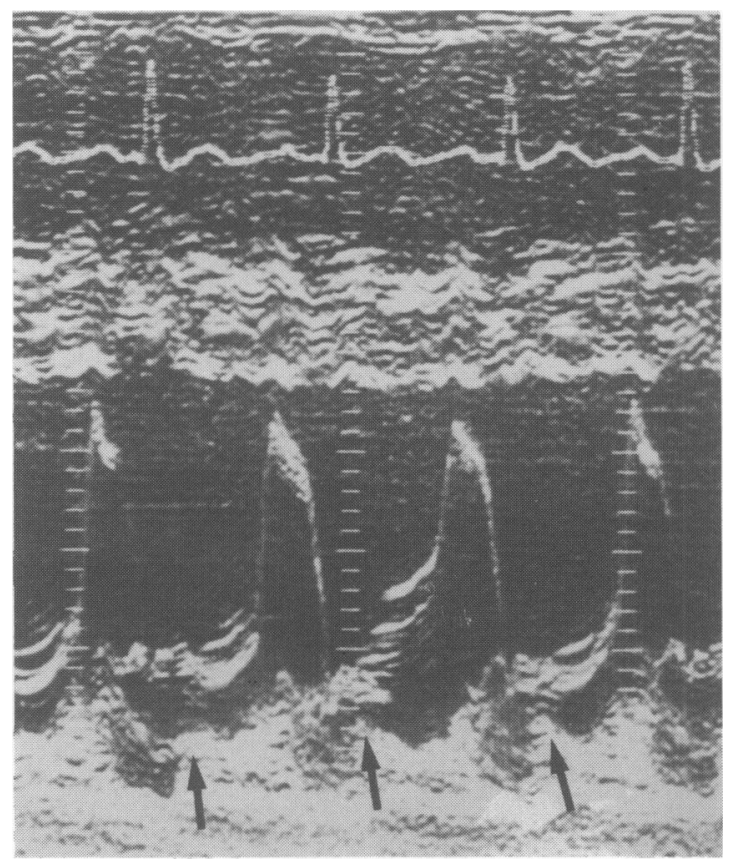

Figure 1 Two dimensional echocardiography showing pansystolic hammocking of the mitral valve.

(C) The Fellowship of Postgraduate Medicine, 1986 
enjoyed good health previously with no previous spontaneous abortions or thrombotic episodes and had no known risk factor to date.

On examination she was found to have a global aphasia with a dense right hemiplegia. Cardiovascular examination was completely normal.

Investigations included normal coagulation and haematological, renal, mineral, hepatic, metabolic and lipid profiles. Urine examination, autoimmune antibody profile and anti-syphilis serology in both blood and cerebrospinal fluid were normal.

Head computed tomographic scanning showed a well defined non-enhancing low density area in the left fronto-temporoparietal region without shift consistent with infarction. Chest radiology, electrocardiography as well as 48 hours Holter monitoring were completely normal. Two dimensional echocardiography showed pansystolic hammocking of the mitral valve (Figure 1).

Bilateral carotid intra-arterial digital subtraction angiograms showed complete occlusion of the left internal carotid artery near its origin with good contrast filling on the right side (Figure 2). Intravenous digital subtraction angiography was done six months later and continued to show total occlusion

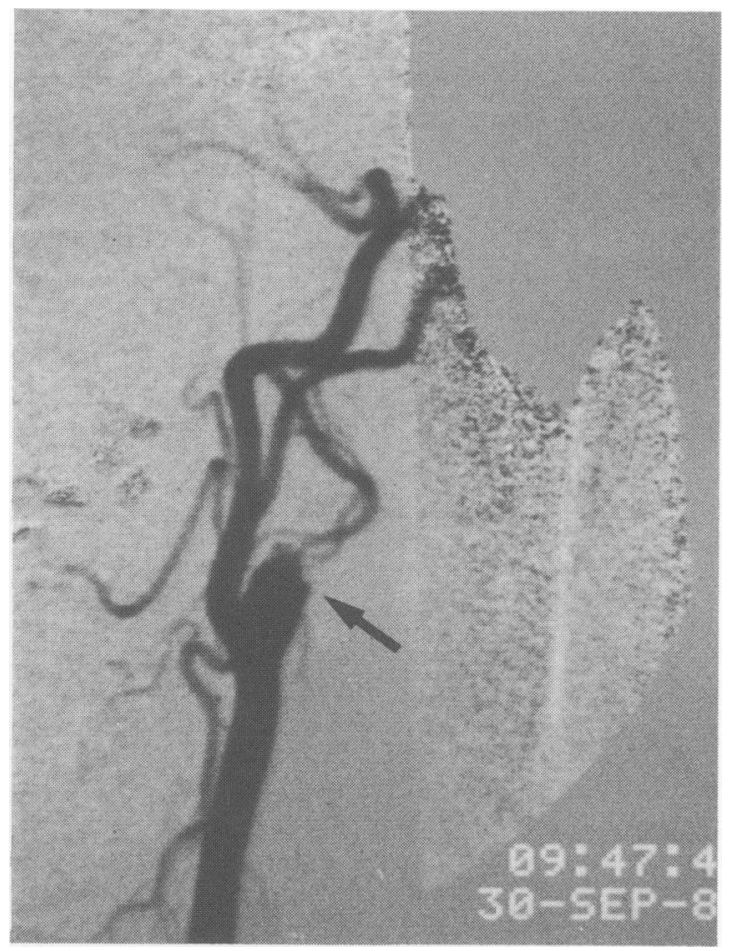

Figure 2 Digital subtraction angiograms showing complete occlusion of the left internal carotid artery near its origin with good contrast filling on the right side. with no evidence of recanalization.

The patient showed little improvement in her clin- $\frac{3}{\mathbb{D}}$

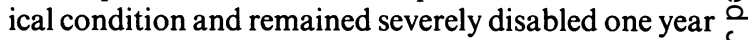
after her stroke.

\section{Discussion}

Cardiac embolism is an important source of stroke. It accounts for $14-16 \%$ of all cases of cerebral infarctions (Mohr et al., 1978; Martin \& Biller, 1984). MVP कs has been reported to be a possible cause particularly in $\vec{\circ}$ the young stroke patient (Barnett et al., 1976; Barnett $\overrightarrow{\vec{\omega}}$ et al., 1980). MVP can be associated with supraven- $\stackrel{\omega}{\sigma}$ tricular arrhythmias particularly atrial fibrillation. 8 The latter even in the absence of other heart disease is 3 . associated with a high incidence of cerebral infarction os (Sherman et al., 1984). There was no evidence of a ? significant arrhythmia in our patient on prolonged $\varlimsup_{\perp}$ monitoring with no evidence of other cardiac disease on chest radiography and two-dimensional echocar- $\vec{N}$ diography. This, however, does not exclude the pos- $\vec{\circ}$ sibility of a sudden dysrhythmia which may provoke embolization. The mechanism of the formation of a $\vec{\nabla}$ thrombus on the surface of a prolapsed valve in the $\stackrel{\oplus}{\varnothing}$ absence of endocarditis is unclear. However, path- $\frac{\Phi}{3}$ ological changes at the margins of the prolapsed valve $\overline{0}$

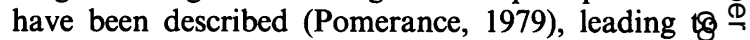
platelet fibrin thrombus over the redundant leaflet $\overrightarrow{0}$ This, in association with paroxysmal atrial fibrillatio may be responsible for embolization.

Two dimensional echocardiography is highly sensitive in detecting MVP but is less sensitive in detecting a left atrial thrombus (Nichol \& Kertesz, 1980; Knopman et al., 1982). No evidence of thrombus was noted in our patient.

It has been reported that very few patients with $\overrightarrow{\bar{O}}$ MVP with primarily cardiac symptoms presenting to the cardiologist develop strokes compared to young patients with MVP and stroke presenting to the neurologist (Jones et al., 1982). Our patient was asymptomatic prior to her ictus and her cardiac monitoring failed to show any significant abnormality.

Total internal carotid artery occlusion at its origin in a patient with MVP has been reported in one patient (Barnett et al., 1980; Barnett, 1982). The sudden onset of the condition makes the diagnosis of an embolic phenomenon likely.

In another series of strokes in patients with MVP a o case of internal carotid artery occlusion at the siphon $\mathrm{N}$ was reported (Watson, 1979). The patient was over 50 N years of age which makes the possibility of an atherosclerotic lesion more likely.

Occlusion of the internal carotid artery in young $\stackrel{O}{=}$ patients with stroke without MVP has also been $\stackrel{\mathcal{D}}{+}$ reported (Barnett, 1982). The angiograms when re- 
peated showed recanalization of the obstructive lesion. This latter occurrence was not the case in our patient where a repeat angiogram six months after the ictus continued to show total occlusion. This suggests that the thrombus is firm and organized. Intracranial branch rather than major vessel occlusion is the recognized feature in patients with MVP and a stroke (Hanson et al., 1980). Although certain authors have reported recurrent cerebral ischaemic events in their

\section{References}

BARNETT, H.J.M. (1982). Embolism in mitral valve prolapse. Annual Review of Medicine, 33, 489.

BARNETT, H.J.M., JONES, M.W., BOUGHNER, D.R. \& KOSTUK, W.J. (1976). Cerebral ischaemic events associated with mitral valve prolapse. Archives of Neurology, 33, 777.

BARNETT, H.J.M., BOUGHNER, D.R., TAYLOR, D.W., COOPER, P.E., KOSTUK, W.J. \& NICHOL, P.M. (1980). Further evidence relating mitral valve prolapse to cerebral ischaemic events. New England Journal of Medicine, 302, 139.

BETON, D.C., BREAR, S.G., EDWARDS, J.D. \& LEONARD, J.C. (1983). Mitral valve prolapse: an assessment of clinical features, associated conditions and prognosis. Quarterly Journal of Medicine, New Series, 52, 150.

HANSON, M.R., CONOMY, J.P. \& HODGMAN, J.R. (1980). Brain events associated with mitral valve prolapse. Stroke, 11, 499.

JONES, H.R., NAGGAR, C.Z. \& SELJAN, M.P. (1982). Mitral valve prolapse and cerebral ischaemic events: A comparison between a neurology population with stroke and a cardiology population with mitral valve prolapse observed for 5 years. Stroke, 13, 451.

KNOPMAN, D.S., ANDERSON, D.C., ASINGER, R.W., GREENLAND, P., MIKELL, F. \& GOOD, D.C. (1982). Indications for echocardiography in patients with ischaemic stroke. Neurology (NY), 32, 1005.

KOUVARAS, G. \& BACOULAS, G. (1984). Association of mitral valve leaflet prolapse with cerebral ischaemic events in the young and early middle aged patients. Quarterly Journal of Medicine, 55, 287. patients with MVP (Barnett et al., 1980) other workers denied the existence of second embolic events (Kouvaras \& Bacoulas, 1984). The evidence thus is not conclusive. We therefore feel that antiplatelet drug prophylaxis is justified for patients who have had a stroke associated with MVP. In conclusion, this case may add weight to the tenuous evidence that a major vessel can be occluded in a young patient with an embolic stroke associated with mitral valve prolapse.

MARKIEWICZ, W., STONER, J., LONDON, E., HUNT, S.A. \& POPO, R.L. (1976). Mitral valve prolapse in one hundred presumably healthy young females. Circulation, 53, 464.

MARTIN, J.G. \& BILLER, J. (1984). Non-specific cerebral emboli of cardiac origin. Archives of Internal Medicine, 144, 1997.

MOHR, J.P., CAPLAN, L.R., MELSKI, J.W., GOLDSTEIN, R.J., DUNCAN, G.W., KISTLER, J.P., PESSIN, M.S. \& BLEICH, H.L. (1978). The Harvard co-operative stroke registry: a prospective registry. Neurology, 28, 754.

NICHOL, P. \& KERTESZ, A. (1979). Two dimensional echocardiographic detection of left atrial thrombus in patients with mitral valve prolapse and strokes (abstract). Circulation (supplement II), 59, 60: 18.

POMERANCE, A. (1969). Ballooning deformity (mucoid degeneration) of atrioventricular valves. British Heart Journal, 31, 343.

PROCACCI, P.M., SAVRAN, S.V., SCHREITER, S.L. \& BRYSON, A.L. (1976). Prevalence of clinical mitral valve prolapse in 1169 women. New England Journal of Medicine, 294, 1086.

SANDOK, B.A. \& GIULIANI, E.R. (1982). Cerebral ischaemic events in patients with mitral valve prolapse. Stroke, 13, 448.

SHERMAN, D.G., GOLDMAN, L. WHITING, R.B., JURGENSEN, K., KASTE, M. \& EASTON, J.D. (1984). Thromboembolism in patients with atrial fibrillation. Archives of Neurology, 41, 708.

WATSON, R.T.,(1979). TIA, stroke and mitral valve prolapse. Neurology, 29, 886. 